\title{
Common Bunt Resistance of Winter Wheat Genotypes Under Artificial Infection
}

\author{
Kuttymurat Tagayev ${ }^{1}$, Aleksey Morgounov ${ }^{2}$, Minura Yessimbekova $^{3}$, Aigul Abugalieya ${ }^{3}$ \\ ${ }^{1}$ Kazakh National Agrarian University, Abay Avenue, 8, Almaty, A26M8G3, Kazakhstan \\ ${ }^{2}$ CIMMYT, P.K. 39 Emek, Ankara, 06511, Turkey \\ ${ }^{3}$ Kazakh Research Institute of Agriculture and Plant Growing, Erlepesova street 1, Almalybak village, Almaty region, B42Y1G2, Ka- \\ zakhstan \\ *Corresponding author E-mail: tagayev.k@mail.ru
}

\begin{abstract}
Common bunt (Tilletia caries) is a seed-transmitted fungal disease in wheat. The resistant cultivars and germplasm lines of wheat will be useful for control this type of disease in organic farming. A set of 75 wheat cultivars and lines from International Winter Wheat Improvement Program (IWWIP) of Turkey were used to determine resistance to common bunt. The experiment was carried out at the Kazakh Research Institute of Agriculture and experimental material was grown in an artificially inoculated nursery during the 2016-2017 season. The productivity of wheat genotypes under artificial infection ranged from $1.13 \mathrm{t} / \mathrm{ha}$ to $7.29 \mathrm{t} / \mathrm{ha}$. The susceptible check to common bunt, GEREK 79 had a high level of susceptibility to common bunt with $59.7 \%$ infected heads. The high mean disease incidence in the nursery was $74.4 \%$. Sixteen genotypes were resistant to disease under artificial inoculation. Out of 75 wheat cutivars, 42 wheat genotypes (56\% of all genotypes) were classified as moderate resistance to disease. Identified resistance genotypes will be useful for breeding programs for forming resistance cultivars to common bunt in Kazakhstan.
\end{abstract}

Keywords: Common bunt; Productivity; Resistance; Wheat; Wheat cultivars; Wheat lines.

\section{Introduction}

Kazakhstan is one of the major wheat producers in the world. The climatic conditions on the Northern Side are very favorable to cultivate cereal crops. The most important sector in agriculture of Kazakhstan is wheat production. Among the CIS countries, Kazakhstan enters the top of three leaders, ranking third after Russia and Ukraine. However, diseases and pests also play an important role in yield reduction in Kazakhstan. Common bunt, known as smut disease is caused by two fungi Tilletia tritici and T. laevis. This disease occur all wheat-planting regions of the world $[1,2]$. It is a dangerous wheat disease, known since ancient times, and produce spore-contaminated seeds [3]. The disease spread in all wheat-growing regions [4]. The common bunt spores, which are from previous crop contaminated seeds, are developed and multiplied, inside the developing in wheat seedlings stage, when the plant attains full maturity stage, they convert the kernel of the wheat into toxic mass of bunt spores. It causes yield loss in common wheat $[5,6]$ and decrease yield quality via the developing of black mass of fungus, which gives smell like fish odor [7]. Suppression of bunt diseases using chemical fungicides is possible by treatment of the seeds, but this way is not effective constantly, and it neither is best choice to control this disease, because cost of fungicides is high, also dangerous for human health, animal health and environment. In addition, chemical treatment is not allowed under organic farming conditions. Although the seed treatment of wheat using fungicides for the control of wheat fungi diseases is widespread. However use of genetic resistance cultivars of wheat is effective and not dangerous way of the disease control in the most of countries, particularly on organic agriculture.
Use of resistant varieties may reduce the losses due to bunt drastically globally. Infection levels in highly susceptible cultivars exceed $80 \%$ of diseased spikes, while in highly resistant cultivars only $0 \%$ diseased spikes were observed [8]. The most effective and economic beneficial method of the control of wheat fungi diseases is using bunt resistant cultivars of wheat $[3,9,10]$. The study of identification of sources of resistance to disease is important for forming resistant wheat cultivars and advanced lines via conventional breeding. Investigation for resistance to common bunt and identification of new sources of resistance are required particularly under organic agriculture conditions [11].

The goal of this study was to identifiy the resistance of wheat cultivars and lines to common bunt under artificial infection. Genetic analysis has also been carried out to evaluate the inheritance of the common bunt resistance.

\section{Materials and Methods}

Common Bunt Resistant Nursery (CBUNT- RN 2015-2016) was prepared and distributed by the International Winter Wheat Improvement Program of Turkey. This nursery was combination of different types of germplasm lines resistant to common bunt (75 wheat genotypes from 7 countries -Turkey, Iran, Kazakhstan, Mexico, Romania, Russia, and USA). The experiments of artificial inoculation with spores of common bunt were conducted in the field condition, in the farming research blocks of Kazakh Research Institute of Agriculture and Growing, Almalybak, Almaty region, Kazakhstan, during the period 2016-2017. The experiments were conducted in a randomized design using three replications. Firstly,seed treatment of wheat seeds with fungicides, and then 
150 seeds have sown from each wheat germplasm. Artificial inoculation of the seeds with spores has done by methods of Borrgardt-Anpilogova [12], using a mixture of isolates from southeast part of Kazakhstan. The spores were obtained from naturally infected plants from the fields of Scientific Research Institute for Biological Safety Problems, Otar, Kazakhstan. For inoculation usage of doses of spores were optimal according to Dumalasova V. and Bartos P. [13]. To provide a total infection, the seeds of wheat cultivars and lines were treated using dose of $0.08 \mathrm{~g}$ spores per 150 seeds according to Nielsen B,J, [14]. The seeds of wheat cultivars and advanced lines were planted in October and in the spring, at the heading stage of wheat, phytopathological evaluation of common bunt in the field condition was carried out. The phytopathological scoring was studied at the heading stage of wheat by the visual evaluation of the infected spikes during the period of June and July, by detecting the black colored spikes at the infected plants, distributed to the husks and, at maturity, the kernels contain dark mass of pathogen colored spores. The total identification of resistance wheat cultivars and advanced lines has done by counting the number of susceptible wheat plants to the total number of sowed plants of each cultivar and line. The evaluation tests has been carried out by scale of Krivchenko which provide level of percent $(\%)$ of infected ears [15].

\section{Results and Discussion}

The 2016-2017 years were very favorable for evaluation of common bunt resistance. The productivity of wheat genotypes under artificial infection ranged from $1.13 \mathrm{t} / \mathrm{ha}$ to $7.29 \mathrm{t} / \mathrm{ha}$. The susceptible check, GEREK 79, had a high level of susceptibility to common bunt with 59.7\% infected heads (table 1). This high level of infection in the susceptible check on cultivar GEREK 79 confirmed that the common bunt infection was successful. Goates (1996) [3] suggested that common bunt resistance evaluation should be considered valid when a susceptible check had more than $50 \%$ infected heads. The two resistant winter genotypes, MUFITBEY and NACIBEY, had similar degrees of resistance with 10.1 and $2.0 \%$ infected heads, respectively. The high mean disease incidence in the nursery was $74.4 \%$. Among 75 lines tested genotypes from CBUNT International nursery, 16 genotypes were resistant to disease under artificial inoculation: PBW343*2/KUKUNA//ATAY/CALVEZ/3/ATAY/GALVEZ87, ORKINOS-1/SUNR23//SONMEZ,

ATAY/GALVEZ87/6/TAST/SPRW/4/ROM-

TAST/BON/3/DIDO//SU92/CI13645/5/F130L.12, MADSEN/MALCOLM//ZARGANA-9/3/BURBOT-6, RINA6/ORKINOS-7, DE9//MERGAN-2,ORKINOS- $1 * 2 / 3 /$ AUS GS50AT34/SUNCO//CUNNINGHAM, KS902709-B-51/BURBOT-4, RANA96/GANSU-3, RINA6/BEZ/NAD//KZM(ES85.24)/3/F900K,

ALMT*3/7/VEE/CMH77A.917//VEE/6/

CMH79A.955/4/AGA/3/SN64*4/CNO67//INIA66/5/NAC, BEZOSTAYA/AE.CYLINDRICA,

ZOSTAYA/TR.MILITINAE//TR.MILITINAE-6,

BE4.CV RODINA/AE/SPELTOIDES $(10 \mathrm{KR})$ and OSTROV. It is $21.3 \%$ of all studied wheat genotypes. The other 42 wheat genotypes (56\% of all genotypes) expressed moderate resistance, which infected around $2.0-27.3 \%$ of ears. The ten wheat lines were susceptible, which showed $31.4-48.2 \%$ of incidence to common bunt infection: TILA/BABAX//PASTOR/4/TAST/SPRW//ZAR/3/ATAY/ GALVEZ87,KUPAVA/BURBOT-4// PYN/2*BAU, KRASNODAR/FRTL/6/ NGDA146/4/YMN/TOB//MCD/3/ LIRA/5/F130L.12,87-461 a 63-555/4/ERIT5887//KS82W409//SPN/3/KRC66/SERI, ALD/SNB// ZARRIN/3/YACO/2*PARUS, QUDS*3/MV17,SANZAR-8/KKTS, $\mathrm{MRS} / \mathrm{CI} 14482 / / \quad \mathrm{YMH} / \mathrm{HYS} / 3 / \quad$ RONDEZVOUS/4/ABI 86*3414X84W063-9939-2//KARL92,KS92WGRC-25 and F08034G1. These genotypes were as susceptible to common bunt. For the tested genotypes, the winter wheat genotypes had a high very susceptibility (seven genotypes; 87-461 a 63555//SAULESKU\#26/PARUS/3/AGRI/NAC//ATTILA,

SAULESKU\#44/ TR810200//GRISET-4, KUPAVA/BURBOT4//PYN/2*BAU, SAULESKU\# 44/TR810200//ZGI, TSAPKI/FARMEC, F07270G2 and susceptible check GEREK 79) to common bunt. On base of received results, which confirmed our assumption that these genotypes are susceptible to the race of south Kazakhstan common bunt.

Table 1: Common bunt resistance of wheat genotypes

\begin{tabular}{|c|c|c|c|c|}
\hline \# & Genotype & Origin* & $\begin{array}{c}\% \text { bunted } \\
\text { ears }\end{array}$ & Yield, t/ha \\
\hline 1 & MUFITBEY (resistant check) & TCI & 10.1 & 6.08 \\
\hline 2 & NACIBEY (resistant check) & TCI & 2.0 & 2.17 \\
\hline 4 & PBW343*2/KUKUNA//ATAY/CALVEZ/3/ATAY/GALVEZ87 & TCI & 0.0 & 3.68 \\
\hline 5 & 87-461 a 63-555//SAULESKU\#26/PARUS/3/AGRI/NAC//ATTILA & TCI & 57.2 & 4.44 \\
\hline 6 & ORKINOS-1/SUNR23//SONMEZ & TCI & 0.0 & 4.50 \\
\hline 7 & ATAY/GALVEZ87/6/TAST/SPRW/4/ROM-TAST/BON/3/DIDO//SU92/CI13645/5/F130L.12 & TCI & 0.0 & 3.35 \\
\hline 8 & MADSEN/MALCOLM//ZARGANA-9/3/BURBOT-6 & TCI & 0.0 & 4.17 \\
\hline 9 & RINA-6/ORKINOS-7 & TCI & 0.0 & 2.58 \\
\hline 10 & SAULESKU\#44/TR810200//GRISET-4 & TCI & 57.2 & 7.29 \\
\hline 11 & ATTILA/BABAX//PASTOR/4/TAST/SPRW//ZAR/3/ATAY/GALVEZ87 & TCI & 47.8 & 2.77 \\
\hline 12 & BURBOT-4/3/OMBUL/ALAMO//MV11 & TCI & 6.1 & 2.12 \\
\hline 13 & FRTL//AGRI//NAC/3/BONITO-36/4/ERIT58-87//KS82W409/SPN/3/KRC66/SERI & TCI & 11.9 & 1.92 \\
\hline 14 & GUN91/MNCH*2//T-2003 & TCI & 15.4 & 3.63 \\
\hline 15 & KRASNODAR/FRTL/6/NGDA146/4/YMN/TOB//MCD/3/LIRA/5/F130L.12 & TCI & 11.1 & 6.24 \\
\hline 17 & SHARK/F44105W2.1//AUS4930.7/2*PASTOR/3/ORKINOS-1 & TCI & 26.5 & 6.08 \\
\hline 18 & GANSU-1/3/AUS GS50AT34/SUNCO//CUNNINGHAM/4/ORKINOS-1 & TCI & 4.2 & 4.83 \\
\hline 19 & BURBOT-4/3/OMBUL/ALAMO//MV11 & TCI & 9.3 & 4.81 \\
\hline 20 & KUPAVA/BURBOT-4//PYN/2*BAU & TCI & 54.8 & 3.05 \\
\hline 21 & DE9//MERGAN-2 & TCI & 0.0 & 2.12 \\
\hline 22 & KRASNODAR/FRTL/6/NGDA146/4/YMN/TOB//MCD/3/LIRA/5/F130L.12 & TCI & 8.6 & 6.17 \\
\hline 23 & 362K2.111//TX71A1039.VI*3/AMI/3/ES14/130L1.12//MNCH & TCI & 10.0 & 5.20 \\
\hline 24 & SELYNKA/MERGAN-1 & TCI & 23.1 & 1.70 \\
\hline 25 & 91-142 A 61/KATIA1//GRIZET-4 & TCI & 10.0 & 4.70 \\
\hline 26 & KUPAVA/BURBOT-4//PYN/2*BAU & TCI & 31.4 & 5.67 \\
\hline 27 & KRASNODAR/FRTL/6/NGDA146/4/YMN/TOB//MCD/3/LIRA/5/F130L.12 & TCI & 34.5 & 4.25 \\
\hline
\end{tabular}




\begin{tabular}{|c|c|c|c|}
\hline 28 & ORKINOS-1*2/3/AUS GS50AT34/SUNCO//CUNNINGHAM & TCI & 0.1 \\
\hline 29 & 87-461 a 63-555/4/ERIT58-87//KS82W409//SPN/3/KRC66/SERI & TCI & 32. \\
\hline 30 & SAULESKU\#44/TR810200//ZGI & TCI & 50. \\
\hline 31 & KRASNODAR/FRTL/6/NGDA146/4/YMN/TOB//MCD/3/LIRA/5/F130L.12 & TCI & 15. \\
\hline 32 & TAM200/KAUZ/4/CHAM6//1D13.1/MLT/3/SHI4414/CROW & TCI & 21. \\
\hline 33 & SHARK/F44105W2.1//CHARA/3/MERGAN-1 & TCI & 15. \\
\hline 34 & ALPU/VR5053(WA\#FM/201/23*2/GS50A) & TCI & 25. \\
\hline 35 & KS902709-B-5-1/BURBOT-4 & TCI & 0.1 \\
\hline 36 & JCAM/EMU//DOVE/3/JGR/4/THK/5/BOEMA & TCI & 12. \\
\hline 37 & BATERA//KEA/TOW/3/TAM200/4/494J6.11/TRAP\#1/BOW/5/TX96V2427 & TCI & 6. \\
\hline 38 & BATERA//KEA/TOW/3/TAM200/4/494J6.11/TRAP\#1/BOW/5/TX96V2427 & TCI & 5.5 \\
\hline 39 & ORKINOS-1/4/JING411//PLK70/LIRA/3/GUN91 & TCI & 15. \\
\hline 40 & GRIZET-4/3/ID\#840335//PIN39/PEW/4/LILIA BG/GT & TCI & 17. \\
\hline 41 & KAMBARA1/ZANDER-17 & TCI & 27. \\
\hline 42 & ADMIS/5/SMB/HN4//SPN/3/WTS//YMH/HYS/4/SAB & TCI & 17. \\
\hline 43 & RANA96/GANSU-3 & TCI & 0.1 \\
\hline 44 & RINA-6/BEZ/NAD//KZM(ES85.24)/3/F900K & TCI & 0.1 \\
\hline 45 & VORONA/3/TOB*2/7C//BUC/4/CHAM6//1D13.1/MLT/3/SHI4414/CROW & TCI & 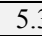 \\
\hline 46 & Son64/4/Wr51/mida//Nt.h/K117/5/Anza/3/Pi//Nor/Hys/4/ Sefid & IR & 20. \\
\hline 47 & ALD/SNB//ZARRIN/3/YACO/2*PARUS & IR & 33. \\
\hline 48 & SPN/MCD//CAMA/3/NZR/4/ALD/SNB*2/5/GASCOGNE & IR & 6.5 \\
\hline 49 & SPN/MCD//CAMA/3/NZR/4/ALD/SNB*2/5/GASCOGNE & IR & 5.9 \\
\hline 50 & CMH79A.955/4/AGA/3/4*SN64/CNO67//INIA66/5/NAC/6/CMH83.25//RSH/8/ZRN & IR & 21. \\
\hline 51 & CMH79A.955/4/AGA/3/4*SN64/CNO67//INIA66/5/NAC/6/CMH83.25//RSH/8/ZRN & IR & 13. \\
\hline 52 & CMH79A.955/4/AGA/3/4*SN64/CNO67//INIA66/5/NAC/6/CMH83.25//RSH/8/ZRN & IR & 17. \\
\hline 53 & QUDS*3/MV17 & IR & 48. \\
\hline 54 & ALMT*3/7/VEE/CMH77A.917//VEE/6/CMH79A.955/4/AGA/3/SN64*4/CNO67//INIA66/5/NAC & IR & 0.1 \\
\hline 55 & CROC 1/AE.SQUARROSA(224)/OPATA & MX & 20. \\
\hline 56 & SANZAR-8/KKTS & MX & 41. \\
\hline 57 & INTENSIVNAYA//PBW343*2//TUKURU & MX-TCI & 23. \\
\hline 58 & TSAPKI/FARMEC & USA & 57. \\
\hline 59 & AMCEL/KS970274/3/KS91048L-2-1/CM112793(CHL)/2*STAR)/HWK1064-6 & USA & 2.2 \\
\hline 60 & DORADE-5/KS980512 & USA & 23. \\
\hline 61 & OR 943576/KS920709 & US--TCI & 5. \\
\hline 62 & MRS/CI14482//YMH/HYS/3/RONDEZVOUS/4/ABI 86*3414X84W063-9939-2//KARL92 & US-TCI & 44. \\
\hline 63 & KS92WGRC-25 & US & 38. \\
\hline 64 & BEZOSTAYA/AE.CYLINDRICA & KAZ & $0 .($ \\
\hline 65 & BEZOSTAYA/TR.MILITINAE//TR.MILITINAE-6 & KAZ & 0.1 \\
\hline 66 & BEZOSTAYA/TR.MILITINAE//TR.MILITINAE-4 & KAZ & $0 .($ \\
\hline 67 & CV.RODINA/AE/SPELTOIDES(10 KR)/S.CEREALE(1.OKR) & RUS & 20. \\
\hline 68 & CV.RODINA/AE/SPELTOIDES(10 KR)/S.CEREALE(1.OKR) & RUS & 5. \\
\hline 69 & CV.RODINA/AE/SPELTOIDES(10 KR) & RUS & 0.1 \\
\hline 70 & F06393GP10 & ROM & 25. \\
\hline 71 & F08034G1 & ROM & 34. \\
\hline 72 & F08347G8 & ROM & 8.9 \\
\hline 73 & OSTROV & ROM & 0.1 \\
\hline 74 & F07270G2 & ROM & 74. \\
\hline 75 & F00628G34-1 & ROM & 4. \\
\hline
\end{tabular}

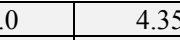

\begin{tabular}{l|l}
0.0 & 4.35 \\
\hline 32.5 & 1.55 \\
\hline 50.0 & 4.50
\end{tabular}

55

5.50

87-461 a 63-555/4/ERIT58-87//KS82W409//SPN/3/KRC66/SERI

SAULESKU\#44/TR810200//ZGI

15.4

5.50

TAM200/KAUZ/4/CHAM6//1D13.1/MLT/3/SHI4414/CROW

JCAM/EMU//DOVE/3/JGR/4/THK/5/BOEMA

BATERA//KEA/TOW/3/TAM200/4/494J6.11/TRAP\#1/BOW/5/TX96V2427

BATERA//KEA/TOW/3/TAM200/4/494J6.11/TRAP\#1/BOW/5/TX96V2427

GRIZET-4/3/ID\#840335//PIN39/PEW/4/LILIA BG/GT

ADMIS/5/SMB/HN4//SPN/3/WTS//YMH/HYS/4/SAB

RANA96/GANSU-3

Son64/4/Wr51/mida//Nt.h/K117/5/Anza/3/Pi//Nor/Hys/4/ Sefid

ALD/SNB//ZARRIN/3/YACO/2*PARUS

CMH79A.955/4/AGA/3/4*SN64/CNO67//INIA66/5/NAC/6/CMH83.25//RSH/8/ZRN

\begin{tabular}{l|l}
\hline 1.2 & 2.80 \\
\hline 5.6 & 3.98
\end{tabular}

\begin{tabular}{l|l}
3.0 & 3.73 \\
\hline & 5.0 \\
\hline
\end{tabular}

3.73

\begin{tabular}{l|l}
\hline 2.9 & 3.20 \\
\hline 6.1 & 2.70
\end{tabular}

\begin{tabular}{ll}
6.1 & 2.70 \\
\hline 9 & 5.27
\end{tabular}

\begin{tabular}{l|l}
\hline .4 & 2.12 \\
\hline
\end{tabular}

17.9

4.55

2.20

\begin{tabular}{l|l}
\hline 7.3 & 2.20 \\
\hline 17.7 & 6.45
\end{tabular}

\begin{tabular}{l|l}
\hline 0 & 5.05 \\
\hline
\end{tabular}

\begin{tabular}{l|l}
0.0 & 5.35 \\
\hline .3 & 4.83
\end{tabular}

\begin{tabular}{l|l}
\hline .0 & 5.24 \\
\hline
\end{tabular}

1.93

\begin{tabular}{l|l}
\hline .5 & 2.78 \\
\hline 5.9 & 2.58
\end{tabular}

\begin{tabular}{c|c}
5.9 & 2.58 \\
\hline 21.7 & 2.85 \\
\hline
\end{tabular}

\begin{tabular}{l|l}
\hline 1.7 & 2.85 \\
\hline 17.9 & 2.78
\end{tabular}

\begin{tabular}{l|l}
\hline 7.5 & 2.65 \\
\hline
\end{tabular}

\begin{tabular}{l|l}
78.2 & 2.63 \\
\hline
\end{tabular}

\begin{tabular}{l|l}
0.0 & 4.83 \\
\hline
\end{tabular}

\begin{tabular}{l|r}
\hline 20.6 & 3.50
\end{tabular}

\begin{tabular}{l|l}
41.9 & 3.68 \\
\hline 23.4 & 2.83
\end{tabular}

\begin{tabular}{l|l}
23.4 & 2.83 \\
\hline 7.2 & 6.47
\end{tabular}

\begin{tabular}{l|l}
\hline .2 & 6.47 \\
\hline 2 & 2.53 \\
\hline
\end{tabular}

\begin{tabular}{l|l}
\hline .8 & 6.35 \\
\hline & 3.47
\end{tabular}

\begin{tabular}{l|l}
5.47 \\
\hline 4.5 & 4.15
\end{tabular}

\begin{tabular}{l|l}
\hline 8.5 & 4.73 \\
\hline 0 & 4.51
\end{tabular}

\begin{tabular}{l|l}
0.0 & 4.51 \\
\hline 0.0 & 1.55
\end{tabular}

\begin{tabular}{l|l}
\hline .0 & 3.68 \\
\hline
\end{tabular}

\begin{tabular}{l|l}
\hline .0 & 3.60 \\
\hline
\end{tabular}

\begin{tabular}{l|l}
\hline .0 & 4.37 \\
\hline .0 & 5.68
\end{tabular}

\begin{tabular}{l|l}
\hline 5.8 & 0.87 \\
\hline
\end{tabular}

\begin{tabular}{l|l}
\hline .8 & 0.87 \\
\hline 3.5 & 4.43
\end{tabular}

\begin{tabular}{l|l}
\hline .9 & 1.13 \\
\hline
\end{tabular}

\begin{tabular}{l|l}
\hline .0 & 1.13 \\
\hline 74.4 & 4.32 \\
\hline
\end{tabular}

*TCI - Turkey-CIMMYT-ICARDA, TR-ESK - Turkey-Eskisher, IR - Iran, MX - Mexico, US - United States of America, KAZ - Kazakhstan, RUS Russia, ROM - Romania

\section{Conclusion}

In conclusion, the common bunt infection was found to decrease the biological yield in the tested genotypes. Artificial inoculation tests for common bunt resistance showed that a large number of resistant genotypes are available in disease condition of southeast part of Kazakhstan. Sixteen genotypes can be considered as valuable resistance sources to common bunt on basis of study using wheat genotypes from CBUNT Nursery of IWWIP. Identified resistance genotypes will be useful for breeding programs to forming resistance cultivars to common bunt in Kazakhstan.

\section{References}

[1] Munjal RL (1966), Bunt disease of wheat. Scientific Reports 3, 33 36.

[2] Bahadur P \& Singh BM (1987), Hill bunt of wheat and its importance. International journal of tropical plant diseases 5, 25-33.

[3] Goates BJ, Common bunt and dwarf bunt. In: Wilcoxson RD \& Saari EE (1996), Bunt and smut diseases of wheat: concepts and methods of disease management. Mexico: CYMMIT, 12-25.
[4] Wilcoxson RD \& Saari EE (1996), Bunt and smut diseases of wheat: concepts and methods of disease management. Mexico: CIMMYT.

[5] Holton CS (1947), Host selectivity as a factor in the establishment of physiologic races of Tilletia caries and $T$. foetida produced by hybridization. Phytopathology 37, 817-821.

[6] Goel LB \& Singh DV (1975), Smuts and bunts of wheat and their control. In Raychaudhuri SP, Varma A, Bhargava KS \& Mehrotra BS (Eds), Advances in mycology and plant pathology. New Delhi: Harsh Kumar at Sagar Printers, 131-147.

[7] Flor HH, Gaines EF \& Smith WK (1932), The effect of bunt on yield of wheat. J. Am. Soc. Agron 24, 778-784.

[8] Dumalasova V \& Bartos P (2006), Resistance of winter wheat cultivars to common bunt, Tilletia tritici (Bjerk.). Wint. and T. Laevis Kühn. Journal of Plant Diseases and Protection 113, 159-163.

[9] Smeltzer DG (1952), Inheritance of resistance to race T-1 of Tilletia caries in Minturki and Cooperatorka wheats. Agronomy Journal 44, 529-533.

[10] Gaudet DA \& Puchalski BL (1989), Status of bunt resistance in western Canadian spring wheat and triticale. Canadian Journal of Plant Science 69, 797-804.

[11] Borgen A (2000), Biological control of common bunt in organic agriculture. Journal of Crop Production 3, 159-174.

[12] Anpilogova MZ (1958), Methods of resistance characteristics of parent materials to fungi diseases and select pair for crossing processes. In Proc. Botanic, genetics and breeding, 33(1), 200-320. 
[13] Dumalasova V \& Bartos P (2008), Effect of inoculum doses on common bunt infection on wheat caused by Tilletia tritici and $T$. Laevis. Czech Journal of Genetics and Plant Breeding 44(2), 73-77.

[14] Nielsen BJ (2003), Strategies for avoiding seed-borne diseases. In Proceedings 11th Australian Barley Technical Symposium and 53rd Australian Cereal Chemistry Conference. 75-79.

[15] Krivchenko VI (1971), Methods of evaluation resistance of cereal crops to bunt diseases. Moscow: Kolos. 